\title{
Effect of Pre-Germination Treatments on Germination and Watering Regimes on the Early Growth of Pycnanthus Angolensis (Welw) Warb
}

\author{
Oboho, E. G. and Igharo, B. \\ Department of Forest resources and Wildlife management, University of Benin, Benin City, Nigeria.
}

\begin{abstract}
The study set to investigate the appropriate means of breaking the dormancy of Pycnanthus angolensis seed as well as determine the optimum watering regime for its early growth. It was conducted in the Department of Forest Resources and Wildlife Management nursery of the University of Benin, Benin City. Five pre-germination treatments (control (old), control (fresh), red aril removal, 48 hours soaking in water, aril and seed coat removal were used for germination studies while three watering regimes (daily, twice and once a week) were applied for growth studies. There were five (5) treatments and four (4) replications for germination studies while three (3) treatments and four (4) replications were used for early growth studies. Complete Randomized Design (CRD) was used. The data collected was analysed using descriptive statistics of frequency and percentages and inferential statistics using one-way Analysis of Variance (ANOVA) at 5\% level of significance. Ducan multiple range test was used to separate means. Germination started thirty-one (31) days after sowing and the period of germination was 18 days after emergence. The aril removal treatment had the best germination performance (83.33\%), followed by seeds soaked for 48 hours (70\%), aril and seed coat removal (36.6\%), control (fresh) (3.3\%) and control (old) (0\%). At the termination of growth study, seedlings had a mean height of $21.15 \mathrm{~cm}, 13.15 \mathrm{~cm}$ and $11.62 \mathrm{~cm}$; mean collar girth of $3.83 \mathrm{~mm}, 3.53 \mathrm{~mm}$ and $3.51 \mathrm{~mm} ; \mathrm{mean}$ number of leaves of 4.96, 4.70 and 4.62, fresh weight of 24.30, 18.30 and 12.75 and a dry weight of 11.45, 8.3 and 6.2 for daily, twice a week and once a week watering regimes respectively. There was significance in the height, fresh and dry weight values of seedlings between watering regimes, but not for collar girth and number of leaves. Fresh seeds with the red aril removed and daily watering regime has been recommended for raising the seedlings, but the species can also tolerate water stress in the nursery.
\end{abstract}

Keywords: Growth, pre-germination, Pycnanthus angolensis, seed, watering

\section{Introduction}

The ever increasing rate of forest loss all over the world makes it necessary to plan for and establish plantations and private free plantings (small scale) of important forest species with a view to meeting the demands for forest products by the people. Dormancy and other seed factors mitigate against easy propagation of many forest tree species. Ease of propagation is intimately tied to seed germination. Oboho (2014) defines germination as the process by which dormant embryo in the seed gets activated grows out of the seedcoat and establishes itself as a seedling. Germination is critical to regeneration and Bello et al. (2011) indicated that the natural population of tree which becoming low has been trace to poor seed germination and seedling survival. Even and adequate germination of seeds sometimes requires seed dormancy to be broken either by natural or artificial means in a process known as pre-treatment. There could be physical, physiological or morphological forms of dormancy in a seed.

Water is very crucial to seed germination and growth of plants. Water used by plants comes mostly from the soil and soil moisture plays an important in germination and plant nutrient uptake. Hence water is vital to success of seedling production especially when large quantities are required for afforestation and reforestation programmes. For tree nurseries, regular watering is necessary to produce good quality seedlings. This is because any stagnation in seedling growth or subsequent mortality translates into economic loss to a nursery operator. This loss can be huge because seedlings take long to reach appropriate size for grafting and transplanting or for sale. (Mngo'omba et al., 2011). The amount of water required by a plant depends on the species type, age, and the prevailing climatic condition of the growing site. Insufficient water could lead to stunted growth on even death of a plant. There is growing concern about water availability particularly in dry land forestry and nursery raised seedlings.

As a result of climate change, meteorologist forecast that water would become scarce in many regions of the world. Availability of permanent water supply has become one of the major challenges in forest tree nursery establishment and management, especially in drier regions. Establishing optimum water requirement for forest tree seedlings in the nursery promotes sustainable water use at reduced cost (Mmgo'omba et al., 2011). The amount of water required by a plant depends on the species type, age and the prevailing climatic condition 
Effect of pre-germination treatments on germination and watering regimes on the early growth of ..

of the growing site. Insufficient water could lead to stunted growth or even death of a plant. There is growing concern about water availability particularly in dry land forestry and nursery raised seedlings.

Pycnanthus angolensis is an important rainforest tree species. Some studies exist concerning screening of it phyto - chemical, antibiotic potential as well as physico - chemical evaluations of its kernel fat. There is however paucity of information in the area of silvicultural protocol for raising the species in the nursery. This study sets out to investigate appropriate seed pre-germination treatment and water requirement for raising its seedlings in the nursery.

Taxonomic notes on Pycnanthus angolensis: (Africana nutmeg or wild nutmeg (welw.) warb Family: Myristicaceae

Trade name: Carra board; Umoghan (Bini)\

Habitat: Upland evergreen forest, wet evergreen forest, moist semi deciduous forest, dry semi deciduous forest, secondary forest and disturbed forest (Asare, 2006).

Distribution: Benin, Ghana. Burkina Faso, Cameroon, Nigeria.

Habitat: African nutmeg is a large, evergreen with a small crown of branches a right angle to the bole, it usually grow from $25-35 \mathrm{~m}$ tall, though trees up to 40m have been recorded (Fern, 2014). It is $60-100$ (150) $\mathrm{cm}$ in diameter, the bole is straight. Cylindrical without buttress, bark is grey, longitudinally fissured, flaking in patches in old trees slash reddish exuding a sticky, honey-coloured sap turning red (Plate 1a). foliag covered in rust coloured felt (Orwa et al., 2009). Leaves are $7-12$ inches long by $2-3.5$ inches broad with margin parallel. It densely clustered flowers are produced between December and March and again in June. Fruit is a rounded capsule (Plate $\mathrm{Ib}$ ), reaching $2.5-3.8 \mathrm{~cm}$ long and $1.9-3.2 \mathrm{~cm}$ in diameter borne in clusters exposing a single black seed with red laicinate aril which resembles that of nutmeg (Plate 1c). There are between $520-540$ seeds per kilogramme.

Soil: It can withstand infertile soils. In countries like Ghana, the trees do well in areas with high rainfall (2000 $2600 \mathrm{~mm} / \mathrm{yr}$ ) and infertile soils (Asare, 2006).

Ethnobotany: The seed fat is used for the production of kombo butter for the potential use in the treatment of arthritis and also show significant anti-inflammatory and anti-oxidant activity. The Kombo butter is used as a stabilizer in cosmetics product. The sap and bark is used to cure headache, cough common cold, dysentery, stomach disorder and waist pain. Sapling and mature trees are used for temporary and permanent shades for cocoa, coffee, banana plantation. Wood is used for veneer peeling, panels, furniture frame, box making, minor journey. Leaf decoction is used as a drink for leprosy, root infusion ac as an anthelmintic (Orwa et al., 2009).

Regeneration: Seeds, wildings and seedlings. Birds and elephant, assist its seed dispersal

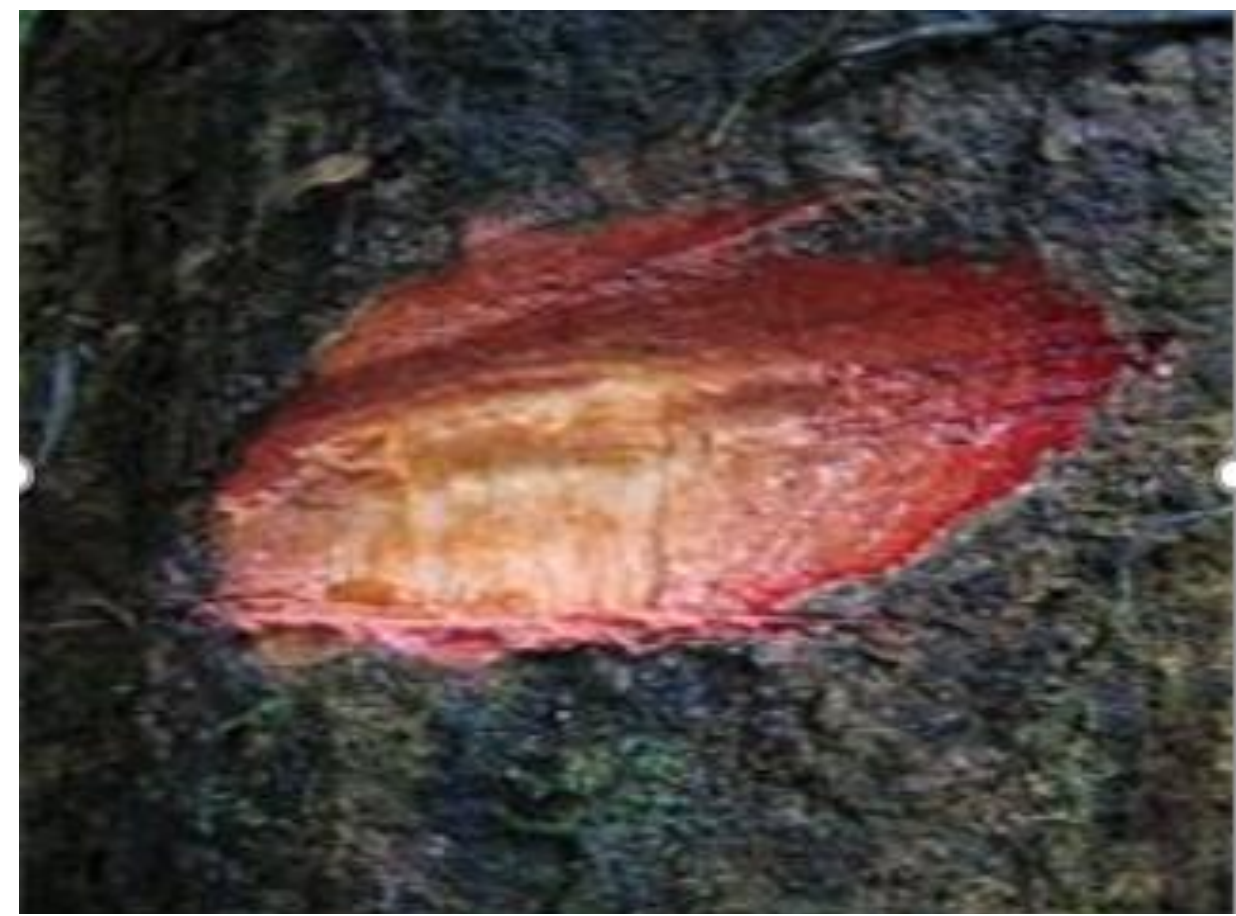

Plate 1a: Slash of Pycnanthus angolensis stem 


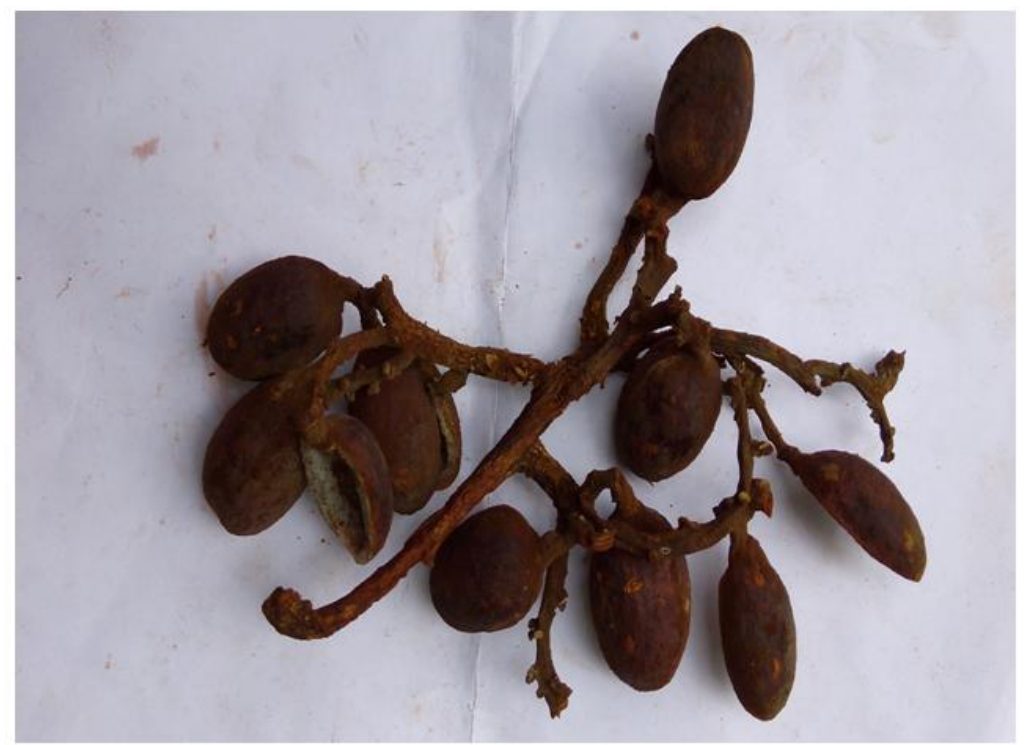

Plate 1b: Fruits of Pycnanthus angolensis

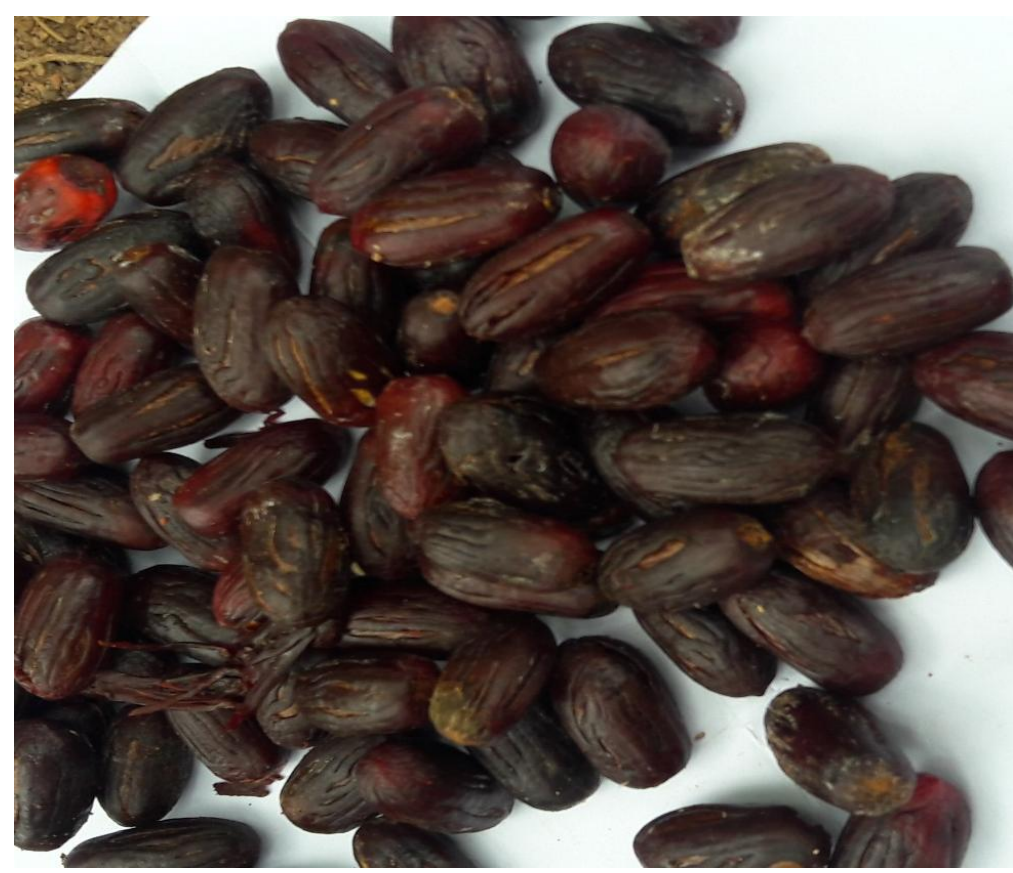

Plate 1c: Seeds of Pycnanthus angolensis

\section{Materials and method}

The experiment was carried out in the nursery of the Department of Forestry Resources and Wildlife Management, University of Benin, Benin City, Nigeria. The GPS location of the nursery in Latitude N06 $24^{\prime} 055^{\prime \prime}$, and longitude E005 $37^{\prime} 404^{\prime \prime}$, precision of $3 \mathrm{~m}$ and an altitude of $134 \mathrm{~m}$ above sea level. The vegetation of Benin City is that of tropical lowland and rainforest and the climatic condition has a bimodal rainfall pattern with long and sometimes short period of uncertain rainfall and an annual mean of about $2300 \mathrm{~mm}$. the mean temperature is about $25.1^{\circ} \mathrm{C}$ (Egherevba et al., 2005). The common tree found here are Alstonia boonei, Antiaris africana, Triplochiton scleroxylon, Celtis zenkeeri, Pycnathus angolensis, Milicia excelsa.

\section{Methodology}

The fruit of Pycnanthus angolensis were collected from a good phenotypic mother tree in Ogba zoo, Benin City, Edo State. The fruits were collected by picking freshly fallen ones from the forest floor. Five hundred (500) fruits were collected after which the seed were extracted from the fruits, sorted and weighed. 
Effect of pre-germination treatments on germination and watering regimes on the early growth of ..

They were separated into batches for the treatments. There were 100 (one hundred) seeds per batch. Garden top soil used to raise seedlings was thoroughly sieved to remove extraneous materials (dead roots, stones, leaves sticks etc), then the poly-pots were filled with it an each filled poly-pot weighed $4.2 \mathrm{~g}$; they were stacked and watered for one week so as to allow unwanted seeds or weeds grow out and it was weeded before sowing the Pycnanthus angolensis seeds. The study was in two part (a) pre-germination, (b) watering regime and growth response.

Control (old) $\left(\mathbf{T}_{1}\right)$

The seed open stored for one month were sown without treatment

Control (fresh) $\left(\mathbf{T}_{2}\right)$

Fresh seeds were sown without any treatment.

Red aril removal $\left(\mathbf{T}_{3}\right)$

The first coat (the outer reddish coat) was removed and seeds sown

48 hours soaking $\left(\mathbf{T}_{4}\right)$

The first (the outer reddish coat) was removed seeds for 48 hours.

Red aril and seedcoat removal $\left(\mathbf{T}_{5}\right)$

The first (outer reddish coat) and the second (inner blackish coat) were removed and seed sown. Observations on germination followed seed sowing. The stage took 8 (eight) weeks. Parameters investigated included day of seedlings emergence, daily germination counts, peak germinating total number of emerged seedlings and germination percentage. There was continuous routine maintenance and weeding done regularly to avoid competition with the seedlings for water nutrient, sunlight and was watered every day except when it rained.

\section{Water Regime and Growth Response Phase}

This followed the germination phase. The germinated seedlings were rearranged into 3 treatments and 4 replications in the screen house. The watering regimes were W1 (daily watering), W2 (twice a week watering) and W3 (once a week watering). One hundred and eight (108) seedlings were used for the study out of which five (5) seedlings were tagged in each replicate and altogether sixty (60) seedling were used for growth parameters data collection.

The parameters included plant height, collar girth and number of leaves, these were taken fortnightly. At the termination of the study the fresh and dry weight of five seedlings were taken per watering regime.

Plant height (cm)

In this study, a $30 \mathrm{~cm}$ rule was used to takes the measurement; the rule was placed at the root collar and then the stem height taken up to the tip of the seedling. Unit of measurement was in centimeter $(\mathrm{cm})$.

\section{Number of Leaves}

This is the total number of leaf count found on the seedling at a particular time. In this study, all leaves on every marked seedling were counted and recorded.

Collar girth (mm)

In this study, the collar girth was measured using a digital Vernier caliper, the unit of measurement was in millimeters ( $\mathrm{mm})$.

Fresh and dry biomass

At the end of study, the fresh biomass of five seedlings per treatment were measured using an electronic weighing balance. The unit of measurement was in grams $(\mathrm{gm})$. The seedlings were later oven dried at $80^{\circ} \mathrm{C}$ until the attainment of constant weight to get the dry biomass value.

\section{EXPERIMENTAL DESIGN AND STATISTICAL ANALYSIS}

The experimental design used was Completely Randomized Design (CRD) with 5 treatments and 4 replications for the pre-germination study while the growth aspect had 3 treatments and 4 replications. The data collected were analyzed using descriptive statistics of frequency and graph, inferential statistics using one - way analysis of variance (ANOVA) and Duncan multiple range test used to compare means at $5 \%$ level of significance.

\section{Results}

The germination of Pycnanthus angolensis was hypogeal (Plate 2) and the trend irregular. The various treatments had varying effects on its germination. T1, T2, T3, T4 and T5 had germination percentages of 0, 3.3, 83.3, 70 and $36.67 \%$ respectively (Table 1 ). Emergence commenced on the $31^{\text {st }}$ day after sowing for T2, T3, T4 and T5. T1 failed to germinate throughout the study. $T_{3}, T_{4}$ and $T_{5}$ attained peak germination at emergence then gradually decreased over time (Fig 1). The first six days of emergence was the most active germination time for the treatments except for $\mathrm{T} 1$ and $\mathrm{T} 2$. The germination period was 18 days after emergence. 


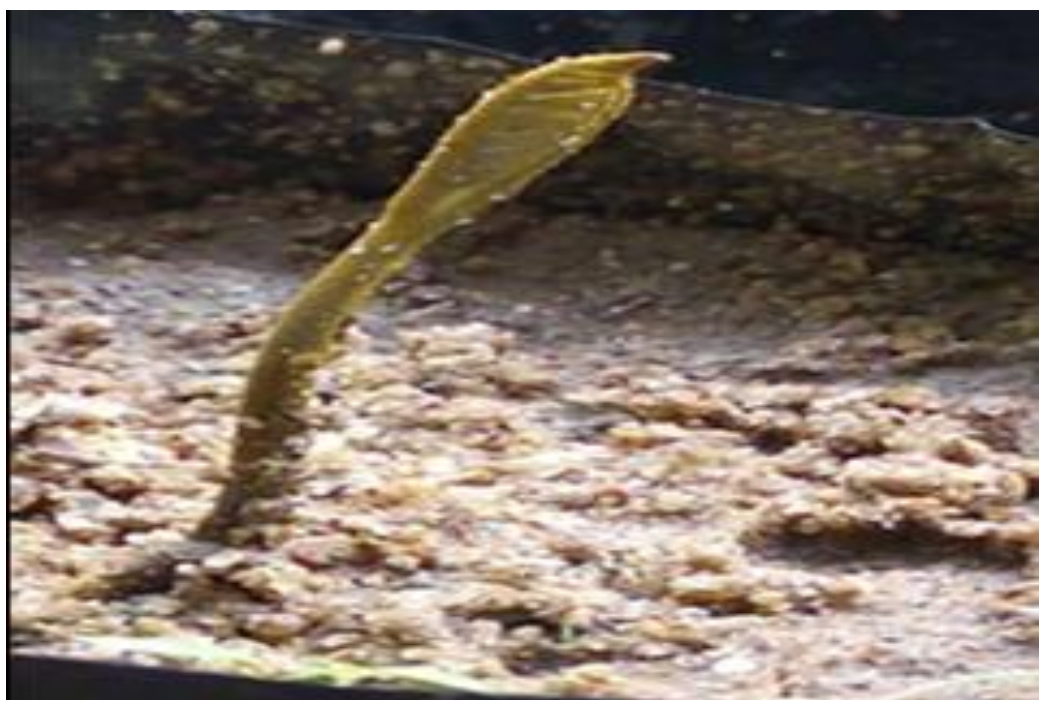

Plate 2: Hypogeal germination of Pycnanthus angolensis seedling

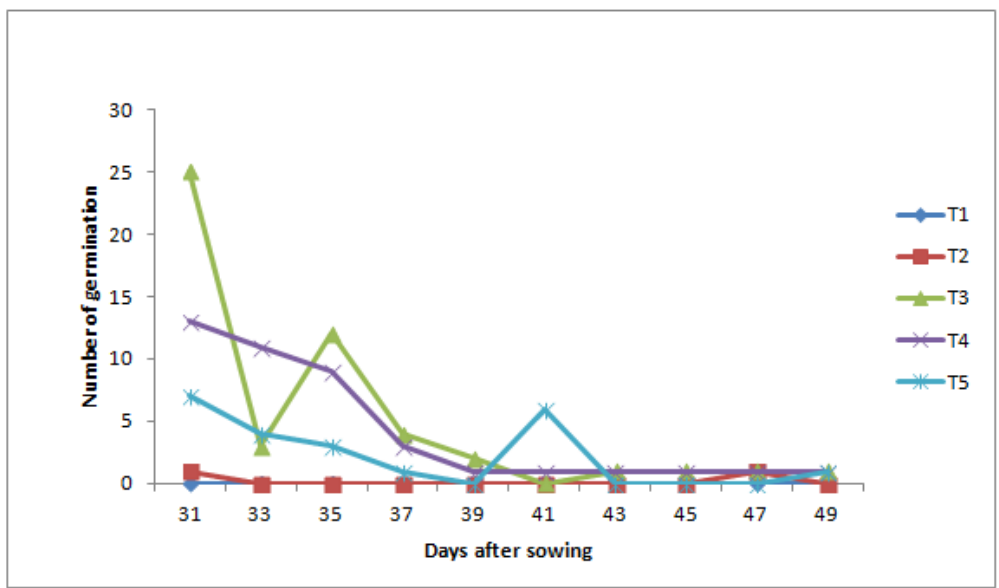

Figure 1: Trend in germination of Pycnanthus angolensis in relation to treatments

\section{WATERING REGIME AND GROWTH}

Height (cm)

At termination of the growth phase, the seedlings had mean height values of $21.15 \mathrm{~cm}, 13.5 \mathrm{~cm}$ and $11.62 \mathrm{~cm}$ for $\mathrm{W} 1, \mathrm{~W} 2, \mathrm{~W} 3$ (Plate 3). The weekly mean increments were $1.51 \mathrm{~cm}, 0.94 \mathrm{~cm}$ and $0.83 \mathrm{~cm}$ for W1, W2 and W3 respectively. There was significant difference $(\mathrm{p}>0.05)$ in height growth of the seedlings between the watering regimes (Table 2).

The height increased progressively with time. All treatments exhibited similar height growth trend irrespective of the watering regimes.

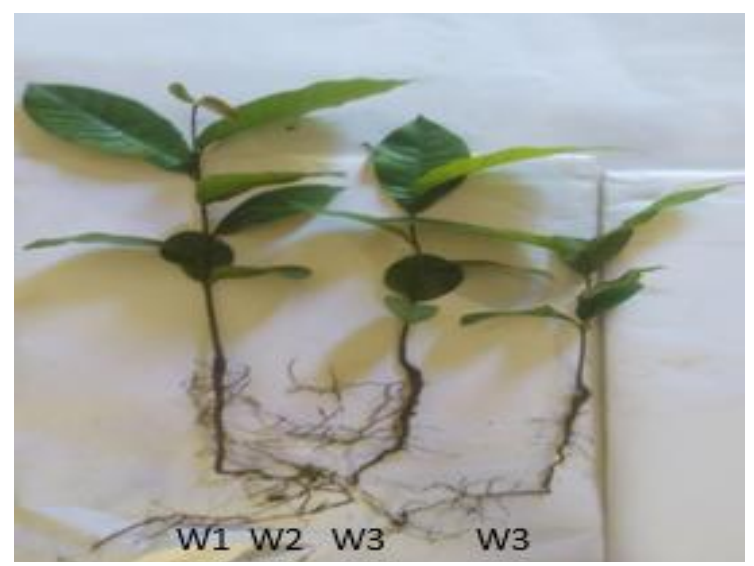

Plate 3: Seedlings of Pycnanthus angolensis under the varying watering regimes 
Effect of pre-germination treatments on germination and watering regimes on the early growth of ..

Table 1: Germination parameters of Pycnanthus angolensis under different treatments

\begin{tabular}{|l|c|c|c|l|}
\hline Treatment & $\begin{array}{l}\text { Days to } \\
\text { emergence }\end{array}$ & $\begin{array}{l}\text { Germination period } \\
\text { (days) }\end{array}$ & $\begin{array}{l}\text { Germination } \\
\text { percentage }(\boldsymbol{\%})\end{array}$ & Peak germination \\
\hline $\mathrm{T}_{1}$ (control old) & - & - & 0 & - \\
\hline $\mathrm{T}_{2}$ (control fresh) & 31 & - & 3.3 & At emergence \\
\hline $\mathrm{T}_{3}$ (aril removed) & 31 & 18 & 83.3 & At emergence \\
\hline $\mathrm{T}_{4}$ (aril removed, soaked) & 31 & 18 & 70 & At emergence \\
\hline $\mathrm{T}_{5}$ (aril + seedcoat removed) & 31 & 18 & 36.6 & At emergence \\
\hline
\end{tabular}

Table 2: Seedling growth parameters of Pycnanthus angolensis under varying watering regimes.

\begin{tabular}{l|c|c|c|c|c}
\hline Watering regime & Plant height $(\mathbf{c m})$ & $\begin{array}{l}\text { Collar girth } \\
(\mathbf{m m})\end{array}$ & $\begin{array}{l}\text { Number of } \\
\text { leaves }\end{array}$ & $\begin{array}{l}\text { Fresh biomass } \\
(\mathbf{g m})\end{array}$ & Dry biomass (gm) \\
\hline $\mathrm{W}_{1}$ & $21.15^{\mathrm{a}}$ & $3.82^{\mathrm{a}}$ & $4.96^{\mathrm{a}}$ & $24.3^{\mathrm{a}}$ & $11.45^{\mathrm{a}}$ \\
$\mathrm{W}_{2}$ & $13.15^{\mathrm{b}}$ & $3.53^{\mathrm{a}}$ & $4.70^{\mathrm{a}}$ & $18.3^{\mathrm{b}}$ & $8.30^{\mathrm{b}}$ \\
$\mathrm{W}_{3}$ & $11.62^{\mathrm{b}}$ & $3.51^{\mathrm{a}}$ & $4.62^{\mathrm{a}}$ & $12.57^{\mathrm{b}}$ & $6.20^{\mathrm{b}}$ \\
\hline $\mathrm{LSD}$ & 6.35 & 1.86 & 2.89 & 9.02 & 5.14 \\
\hline
\end{tabular}

\section{Collar girth}

The mean collar girth were $3.82,3.53$ and $3.5 / \mathrm{mm}$ for $\mathrm{W} 1$, W2 and W3 respectively. Mean weekly increment being $0.27,0.25$ and $0.25 \mathrm{~mm}$ for the respective watering regimes. There was no significant difference between the values. All treatments showed similar growth patterns.

\section{Number of leaves}

The mean number of leaves values for the seedlings were of 4.96, 4.70 and 4.62 for W1, W2 and W3 respectively. The weekly mean increment was $0.35,0.34$ and 0.33 . There was no significant difference $(p>0.05)$ in number of leaves of the seedlings between the watering regimes.

The number of leaves increased progressively with time. All treatments exhibited similar increment in number of leaves in the trend irrespective of the watering regime.

\section{Fresh and Dry weight}

The seedling fresh weight were $24.3,18.3$ and $12.57 \mathrm{gm}$ for $\mathrm{W} 1$, W2, and W3 respectively. The dry weight values were $11.45,8.3$ and $6.2 \mathrm{gm}$ for the respective watering regimes. Values were significantly different between the regimes with the $\mathrm{W} 1$ being the best.

\section{Discussion}

There was no germination in $\mathrm{T}_{1}$ where seed lot had been stored for 4 weeks.This is an indication that time greatly reduced the seed viability of Pycnanthus angolensis and its seed is recalcitrant. This is in agreement with the view of et al., (2009) who also noted that the seeds of Pycnanthus angolensis were recalcitrant and it has low viability period.

Germination was very low in $\mathrm{T}_{2}$. This is an indication that without any pre-germination treatment, germination was difficult for this species. This is due to the fact that the outer seedcoat contains chemical depositions which delayed or prevented water from penetrating the seeds to effect germination process. The findings are in agreement with the views of Oboho and Urughu (2004) who noted that seedcoat of Garcinia kola had oily content which impacted dormancy and prevented germination of the seed without pre-treatment. $\mathrm{T}_{3}$ had the highest germination, this is because the removal of the outer aril coating imposed $t$ restraint that could have delayed the germination process and therefore enhance imbibition of water and oxygen enhancing enzymatic activities for stimulating germination. The findings are in agreement with the view of Saced and Thanis (2006) who noted that removal of seedcoat resulted in the promotion and final germination rate of Pinus geraadiana, it is also in agreement with the work of Assesh and Sushma (2013) who noted that the removal of seedcoat contribute to improving the regeneration of Quercus serrata. Germination was good in $\mathrm{T}_{4}$ (although lower than $\mathrm{T}_{3}$ ). The result showed that soaking of seeds for the 48hours improved germination and this was probably due to the increase in hydrolytic enzyme. This is in agreement with the work of Aminu (2012) who reported that soaking of seeds in water increase germination percentage. It could be worthwhile to however investigate this treatment using 24hours of soaking to determine response of this crop under fewer hours of soaking. Germination was poor in $T_{5}$, this is because the outer red and inner brownish seedcoat removal exposed the embryo to too much water which might have inhibited respiration and enzymatic action within the cotyledon to effect stimulation of the embryo to germinate well (Oboho, 2015). Observed the lowest germination percentage with decoated Gambeya albida and opined that seed coat removal was detrimental to Gambeya albida seed germination. This is however contrary to the work of Agboola and Etejere (1991) who noted that the removal of seedcoat improve germination of Leucaena leucocephela.

All the physiological process in plant take place in water medium. Water is the major constituent of any living organisms which involve the important biochemical processes. 
Effect of pre-germination treatments on germination and watering regimes on the early growth of ..

The result of this present study showed that the height growth of P.angolensis seedlings responded significantly to the watering regimes.Seedlings under $\mathrm{W}_{1}$ water regime gave the best result in the investigated growth parameters, particularly height. This is an agreement with the views of Gbadamosi (2014) who noted that daily watering application increased seedling height and that seedlings perform better in unstressed condition when compared with a six-day interval for Persea americana. This observation is constituent with the report of Majumdar (2010) who stated that when adequate water is available, plant cells remains turgid and plants retain their form and structure. This is also in agreement with the view of Agele et al., (2016) who reported that daily watering increased seedling height of $V$. paradoxa.

In this study the growth of collar girth and number of leaves were not statistically significant but numerically different for Pycnanthus angolensis seedlings under the different watering regimes. This is in agreement with the views Bello et al., (2011) who noted that the three watering regimes did not cause any significant change in the number of leaves and collar girth for Acacia seyal and Acacia sieberiana. Even though the values for girth and number of leaves were not statistically different, the values for seedlings fresh and dry weights were statistically different. Such difference could therefore be the result of smaller leaf sizes observed in the seedlings of the lower watering regimes. Leaf size is very crucial in photosynthesis and protoplasm build up hence the higher biomass under the higher watering regime.

In this study, fresh and dry weight of $P$. angolensis were higher in $\mathrm{W} 1$ than $\mathrm{W} 2$ and $\mathrm{W} 3$, Gonzales et al (2009) made similar observation that daily watering increased the fresh and dry weight of Chenopodium quinoa. This is however contrary to the view of Sale (2015) who noted that the fresh and dry weight of root and shoot was found not to be significantly different in the three watering regimes

\section{Conclusion}

Pycnanthus angolensis exhibited hypogeal type of germination. Germination commenced 31 days after sowing and peak germination attained at emergence irrespective of treatment. The removal of the red aril effected the best germination percentage. Seeds open stored for one month did not germinate and fresh untreated seeds had very poor germination. The seed is recalcitrant and needs pre-treatment. There was significant difference in height, fresh and dry biomass in relation to watering regime; the daily watering being best for growth. Number of leaves were numerically similar for the watering regimes but smaller in sizes as the water decreased. It is recommended that fresh seed with the red aril removed be sown in order to have high germination and daily watering regime is best for its seedling growth.

\section{References}

[1]. Agboola,, D. A. (1995). Studies on dormancy and germination of seeds of Prosopis africana . Nigerian Journal of Botany 8: 45 56.

[2]. Agboola, D. A. and Etejere, E. O. (1991). Studies on seed dormancy of selected economic tropical species. Nigerian Journal of Botany 4: 115 - 126 .

[3]. Agele, S. O., Osaigbovo, A. U., Ogedegbe, S. A. and Nwanwe, A. K. (2016). Effects of watering regime, organic manuring and mycorrizal inoculation on the growth and development of shea butter (Vitellaria paradoxa) seedlings. International Journal of Agricultural Policy and Research, 4 (3): 35 - 45.

[4]. Amusa, T. O. (2010). Effects of three pre-treatment techniques on dormancy and germination of seeds of Afzelia africana. Journal of Horticulture and Forestry, 3 (4): 96 - 103.

[5]. Aseesh, P. and Sushma, T. (2013). Effect of pre-sowing treatments on seed germination in Quercus serrata and Quercus semecarpifolia. International Journal of Biodiversity and Conservation, 5 (12): 791 - 795

[6]. Bello, A. G., Isah, A. D. and Maman, A. (2011). Effect of potting mixture and watering regime on early growth of Acacia seyal and Acacia sieberiana in semi and environment at Nigeria sustainable Agricultural Research, 3: 3 .

[7]. Gbadamosi, A. e. (2013). Effect of watering r3egimne and water quality on the early seeding growth of Fricalima nitida. Sustainable Agricultural Research, 3: $2-6$.

[8]. Majumder, A. L., Segupta, S., and Goswanu, L. (2010). Osmolytes regulations in abiotic stress. Agroforestry System, 349 - 370.

[9]. Mngoomba, S. A., Festus, K. A., Guoleta, S. D., Ajayi, C. Betserai, A. N. and Ramri, J. (2010). Water application and frequency effect on seeding survival and growth of Vangeria infausta and Persea americana. Journal of Biotechnology, 10 (9): 1593 - 1599.

[10]. Oboho, E. G. and Urughu, J. A. (2010). Effect of pregermination treatments on early growth of Garcinia kola. African Journal of General Agriculture 6: $4-8$

[11]. Orwa, C. Mutual, A., Kinat, R., Jamnadass, R. and Antony, S. (2009). Agroforestry Database, a tree reference and selection guide version 4.0 (http://www.agroforestry.org/sites/treadbs/ freeedatabases.asp).

[12]. Saced, M. and Thanis, C. A. (2006). The effects of seed coat removal on seed germination of Pinus gerarolina wallich ex. Don. 1 (3): $174-177$ 